[-Jispania, LVIII/2, núm. 199 (19\%8)

\title{
HISTORIA URBANA Y MEZZOGIORNO DE ITALIA EN LA EDAD MODERNA: PROPUESTA DE UN CUESTIONARIO
}

\author{
por
}

\section{AURELIO MUSI}

Università degli Studi di Salerno.

RESUMEN: La bistoria de la urbaniqación no ba sido aperas objeto de análisis en el caso del Mezzogiono de Italia, en parte debido a las visiones estereotipadas sobre esta región bistórica y sobre las funciones de las ciudades. El artículo se origina en las resoluciones adoptadas por un encuentro realizado por especialistas en la Edad Moderna del sur de Italia de cara a realizar un estudio riguroso y detallado sobre los rasgos comunes y las diferencias en sus sistemas urbanos que permita sintetizar la especificidad de la urbanización de la Italia Meridional a largo plazo. El autor recorre los distintos niveles de estudio que se programan para los próximos años, estableciendo sus bases metodológicas y unas primeras bipótesis de trabajo.

PALABras ClaVE: Urbanizaciōn. Italia. Mezzogiorno. Edad Moderna. Métodos de investigación. Conceptos. Sicilia. Reino de Nápoles.

ABSTRACT: The bistory of urbanization bas barely been analyzed for the Mezzogiorno in Italy. This bas partly been due to the persistence of stereotypes in Italian bistoriograpby, and partly due to the current definition of city functions. The article results from a meeting of specialists in Early Modern soutbern Italian bistory organized to undertake the rigorous and detailed study of the common features and the differences witbin the urban systems of the Mezzogiorno, in order to synthesize the specific character of urbanization in soutbern Italy over the long term. The author outlines the main areas under study and establishes its methodological foundations and first bypotheses.

KEY WORDS: Urbanization. Italy. Mezzogiorno. Early Modern Period. Research methods. Concepts. Sicily. Kingdom of Naples.

\section{LA DIFÍCIL IDENTIDAD DEL SUJETO “CIUDAD» EN EL MEZZOGIORNO DE LA EDAD MODERNA}

Que el binomio ciudad/Mezzogiorno de Italia en la Edad Moderna no había encontrado ni ha encontrado todavia interés histótico e historiográfico, que ha sido confinado a los márgenes tanto de la investigación empírica como del debate teórico y metodológico, resalta con plena evidencia a través de una ejem- 
plificación: el análisis de los últimos diez años de la revista Storia Urbana, cuyo subtítulo es Rivista di studi sulle trasformazioni della città e del territorio in età moderna. $\mathrm{El}$ peso y el lugar del Mezzogiorno son prácticamente insignificantes. En ella aparece un único ensayo de carácter comprehensivo, pero dedicado a la primera mitad del siglo XVIII. Los objetos principales de investigación de los escasos artículos publicados en la revista son el movimiento demogtáfico, la transformación de la propiedad feudal, la relación entre propiedad eclesiástica y contexto urbano, las reconstrucciones tras los terremotos y los planos de ampliación urbanística.

La opción de escoger esta línea editorial en lugar de otras posibles depende en primer lugar de la relevancia que los temas arriba señalados han tenido y todavía poseen en la historiografia meridional: relevancia, debe quedar claro, del todo legítima, no arbitraria, ligada como está al peso objetivo de dichos temas en la realidad histórica del Mezzogiorno. En segundo lugat, la opción respeta la estructura de la dirección de Storia urbana, compuesta por urbanistas, demógtafos, historiadores económicos e historiadores contemporáneos. Pero esta miscelánea multidisciplinar, que podría favorecer una estrategia de atención hacia la relación entre contenidos, orientaciones y métodos de análisis, no se transforma en una actitud interdisciplinar. no se dedica ningún ensayo a problemas de definición e identidad del sujeto «ciudad del Mezzogiorno de Italia»; los objetos específicos de investigación apatecen como previamente incluidos en el continente «ciudad».

Por consiguiente, ni entre los historiadores urbanos propiamente dichos ni entre los diversos especialistas comprometidos e interesados han sido ofrecidas, en estos últimos años, contribuciones particularmente significativas, ni sobre el plano de los contenidos ni sobre el plano de los métodos, para el conocimiento de la historia de la ciudad meridional en la Edad Moderna. Antes bien, se hace necesario acudir a algunas obras colectivas y a iniciativas editoriales recientes, promovidas principalmente por historiadores por asi decir generales del Mezzogiono altomoderno.

Entre las primeras destaca ante todo la Storia di Bari nell'antico regime editada por Angelo Massafra y Francesco Tateo ${ }^{1}$. En ella el problema de la formación histórica de la ciudad es presentado con fuerza y constituye el filo que liga entre sí todas las temáticas abordadas. Las estratificaciones sociales y profesionales, fuertemente influídas por las funciones urbanas y por sus procesos de transformación, son reconstruídas en relación con el espacio marítimo de la ciudad, con el espacio comercial a la sombra de la catedral de San Nicola, con las formas de poder y de gobierno urbano. Juntas contribuyen a fijar la identidad histórica moderna de Bari bien sea la de su anomalia -por ese ugran número de poblaciones pequeñas diseminadas en el entorno y que se dicen aldeas de Bariv, según las palabras del ilustrado Giuseppe Maria Galanti-- bien sea en sus relaciones con la capital del Reino, Nápoles. En definitiva queda claro por la com-

1 MASSAFra, A. y TATEO, F. (eds.), Storia di Bari nell'antico regime, Bari, 1991, 2 vols.

Hispania, LVIII/2, ním 199 (1998) 471-488 
plejidad de las contribuciones que durante toda la Edad Moderna Bari ha desempeñado en sus relaciones con su entorno «un papel insustituible de bisagra con los mercados exteriores a la provincia y al Reino, de mercado de consumo para una parte de las mercancías que eran transportadas al interior de los muros urbanos y, en suma, de lugar en el que se producían mercancías, sobre todo manufacturas y servicios, que después eran irradiadas por el territorio circundante» ${ }^{2}$. La atención a la Apulia urbana es también significativa. Algunas de sus provincias, sobre todo durante la Baja Edad Media, tenían por núcleo central una ciudad. Pensemos en la Terra d'Otranto, con sus centros de consumo de cultura y de productos de lujo ${ }^{3}$. Pensemos en la incidencia que sobre la fisonomía urbana de Apulia venía teniendo la relación entre las ciudades meridionales de la región - Brindisi en particular-y el mercado internacional desde la era normando-suaba. Las investigaciones recientes explican en parte las modificaciones de las jerarquías territoriales de Apulia y la dislocación periférica de algunos centros particularmente importantes entre la Baja Edad Media y la primera Edad Moderna, pero también la continuidad y la persistencia de identidades urbanas fuertes, por así decir, incluso después del proceso de "provincialización» y de "periferización» que ha experimentado el Mezzogiono durante la crisis del siglo XVII ${ }^{4}$.

Se han dedicado numerosas investigaciones a las ciudades de la Campania ${ }^{5}$. En síntesis, los resultados que pueden considerarse adquiridos por éstas son los siguientes:

1) la primacía de Nápoles capital, que condiciona el desarrollo de los centros urbanos de esta región;

2) ninguna ciudad consigue ser el centro de su periferia provincial;

3) una provincia, el Principato Citra, proporciona la imagen de un avanzado policentrismo, de una miríada de «ciudades pequeñas y medianas» - en seguida quedará claro el sentido de esta definición- sobre el que gravitan decenas y decenas de territorios menores, en un tejido interconectado muy tupido;

4) en la compleja tipología del estatuto jurídico de los centros urbanos, se distinguen dos ciudades: Avellino, durante dos siglos y medio centro del «estado feudaly de los Caracciolo, hasta la destrucción del feudalismo; y Benevento, ciudad pontificia pero con relaciones muy sólidas con la realidad económica, social y política del Reino de Nápoles.

2 MASSAFRA, A., "Ceti e ptofessioni nell'antico regime» en MASSAFRA, A. y TATEO, F., op. cit., pág. 36.

3 VISCEGLIA, M. A., Territorio, feudo e potere locale. Terra d'Otranto tra Medioeso ed età moderna, Napoli, 1988, pág. 144.

4 AA.VV. Storia di Lecce, RUSSO, S. (ed.), Storia di Foggia in età moderna, Bari, 1992; VISCEGLIA, M. A., $\not p$. cit.

5 Una amplia teseña puede verse en MUSi, A., «Le piccole e medie città nella storia moderna del Mezzogiono continentale», Rassegna Storica Salernitana, 22, 1995, págs. 154 y ss. 
Los estudios sobre la Calabria altomoderna han puesto de manifiesto algunos elementos de su historia urbana ${ }^{6}$. Conviene recordarlos esquemáticamente:

a) las ciudades desarrollan una función limitada en el cuadro de la vida económica y social de la región;

b) también aquí, como en otras partes, el comercio, los oficios, las actividades profesionales y las manufacturas dan el tono a ciudades como Cosenza, Catanzaro, Reggio, Crotone, Monteleone, etc.;

c) el control de las funciones económicas urbanas más importantes es ostentado por barones y mercaderes forasteros;

d) la coyuntura positiva del Quinientos promueve la concentración y el progreso de funciones urbanas: «basta pensar —escribe Galasso- en la facilidad y la rapidez con que Reggio se repone de las numerosas devastaciones berberiscas. El desarrollo de la vida civil tiene incluso un reconocimiento en el plano administrativo con la institución de una Audiencia provincial incluso en la parte meridional de la región, tradicionalmente dependiente de la Audiencia de Cosenza; y no carece de importancia el hecho de que al menos tres centros - Reggio, Seminara y Catanzaro- compiten entre sí por el privilegio de la ubicación de la Audiencias 7;

5) el cierre oligárquico en los comuni durante la crisis del siglo XVII incide sobre el declive de las funciones urbanas en Calabria.

En comparación con Campania, Apulia y Calabria, la atención historiográfica orientada hacia la realidad urbana moderna de otras regiones 6 t l Mezzogiorno continental ha sido menor.

Para la periodización de la génesis de algunas funciones urb:rnas destinadas a caracterizar la duración media de la identidad ciudadana da I Mezzogiorno, tienen particular interés estudios recientes sobre el área de los Abruzzi. Conviene recordar especialmente las investigaciones de A. Bulgarelli Lukacs sobre la incidencia del desarrollo de la ferias en la identidad urbana de Lanciano durante el siglo XV ${ }^{8}$; de A. de Mateis y G. Sabatini sobre las

6 GALASso, G., Economia e società nella Calabria del Cinquecento, Napoli, 1994; AlLEGRA, L. y DE LoRENZO, R. (eds.), Città di periferia. Cosenza nellOttocento, Messina, 1996; AA.VV. Catanzaro. Storia, cultura, economia, Saveria Mannelli, 1994; AA.VV. Cosenza. Storia, cultura, economia, Saveria Mannelli, 1991; AA.VV. Crotone. Storia, cultura, economia, Saveria Mannelli, 1992; AA.VV. Gioia Tauro nel contexto storico calabrese. Atti del convegno di studi, Oppido Mamertina, 1996; AA.VV. Reggio Calabria. Storia, cultura, economia, Saveria Mannelli, 1993; AA.VV. Vibo Valentia. Storia, cultura, economia, Saveria Mannelli, 1995; Cingari, G. Storia delle città italiane. Reggio Calabria, Bari, 1988; CURRO, L. y RESIIFO, G., Le città nella storia d'Italia. Reggio Calabria, Bari, 1991; PLACANICA, A., LTiade funesta. Storia del terremoto calabro-messinese del 1783, Roma-Reggio Calabria, 1982; Idem, II filosofo e la catastrofe. Un terremoto del Settecento, Torino, 1985; RUBINO, G. y TET, M. A., Le cittì nella storia d'Talia. Catanzaro, Bari, 1987.

7 GALASSO, G., op. cit., pág. 225.

8 BULGARELI LUKACS, $A$, "Da fiera a città: sviluppo fieristico e identità urbana a Lanciano tra XIV e XV sécolo", Archivio Storico de/Sannio, 1, 1996, págs. 271-292.

Hihpania, LVIII/2, núm 199 (1998) 471-488 
relaciones entre l'Aquila y sus términos "; y de M. R. Berardi sobre las funciones religiosas de l'Aquila ${ }^{10}$.

Incluso una región como Bassilicata, caracterizada por la escasísima presencia de polos de atracción urbana, ha recibido recientemente una cierta atención sobre todo en lo que respecta a las tipologías de asentamientos y las funciones históricas de Potenza y Matera ${ }^{11}$.

Con todo, a pesar de la significativa producción reseñada - y otros estudios que se escapan al que escribe- - se puede decir, sin temor a equivocación, que el sujeto «ciudad» está en gran medida por definir como objeto historiográfico en la historia del Mezzogiorno moderno. Esto no significa - se entiende-que el problema «ciudad» haya estado ausente de la tradición intelectual e historiográfica del Mezzogiorno. Este tema o problema se ha presentado de tres maneras $o$ en tres horizontes diferentes.

El primero, que ha condicionado y condiciona todavía en buena medida muchos análisis, puede ser sintetizado en la dualidad entre la Italia de las ciudades-república medievales, cuna de la «libertad» y de las instituciones políticas modernas, y la Italia de la baja tasa de urbanización y, por consiguiente, de «civilizacións política: es notorio que uno de los padres fundadores de esta distinción fue Sismondi ${ }^{12}$. Si la vida es acción en comunidad, que es el verdadero motor de la historia, la ciudad es la sede principal de las decisiones políticamente relevantes. Y la versión italiana más importante del hacer en comunidad fue el Comune: quien dice Comune quiere decir inmediatamente Ciudad-Estado. En sustancia, reflexionando sobre tal identidad se ha establecido la diferencia interna en el desarrollo histórico italiano entre el área centro-septentrional del país y el área meridional. En el Mezzogiono italiano, los gastaldati lombardos provocaron una ruptura de los antiguos ordenamientos municipales romanos. Como ha puesto de manifiesto Giuseppe Galasso, los ducados de la Campania -Nápoles, Gaeta, Amalfi, Sorrento- no constituyeron un fenómeno de desarrollo comunal, no se convirtieron en las primeras repúblicas del Medievo debido al carácter dinástico y absolutista del poder, controlado por potentados y dinastias locales de base esencialmente fundiaria, también en presencia de una vivaz fisonomía marinera y comercial. El Reino normando hizo en adelante imposible la autonomía política de los Comune. Pero la aspiración a la autonomía no era sentida con sinceridad: no se encuentran leyes de ciudad, alianzas. La ciudad meridional vive de manera atomística. En las relaciones con el cam-

9 DE MATTEIS, A., L'Aquila e il contado. Demografia e fiscalità (secoli XV'XVIII), Napoli, 1973; SABATINI, G., Proprietà e proprietari a L'A quila e nel contado. Le rilievazioni catastrali in età spagnola, Napoli, 1995.

10 BERARDI, M. R., (Da città-contado a città-santuario: l'Aquila tra XIV e XV secolo", $A r$ chivio Storico del Sannio, 1, 1996, págs. 235-269.

11 SANNINO, A. L., Territorio e popolazione a Potenza nell'età moderna, Roma, 1990; MURANO, M., Storia di una società rurale. La Basilicata nell'Ottocento, Bari, 1994.

12 SIMONDE DE SISMONDI, J. Ch. L., Storie delle Repubbliche italiane, Turín, 1996 (introducción de P. Schiera). 
po, ni siquiera las ciudades meridionales más grandes tuvieron la fuerza y la intención concreta de someter el territorio feudal circundante: el predominio constante de los grupos feudales, las relaciones ciudad-campo favorables al campo, la caracterización rural de gran parte de los centros habitados meridionales y la economía señorial como esqueleto fundamental, continuaron siendo factores de larga duración de la historia del Mezzogiono. La organización regular comunal que se difundió en el Mezzogionno bajomedieval fue en gran medida el producto de la acción unitaria y constructiva del Estado monátquico ${ }^{13}$. Naturalmente, esta reflexión historiográfica más madura, al poner en evidencia la naturaleza de las diferencias entre el comune centro-septentrional y el comune meridional de Italia, se diferencia por tanto de la visión de Sismondi porque no disuelve la ciudad en el comune, y subraya la contribución original que incluso la historia del Mezzogiorno ha realizado a la construcción de una civilización política nacional.

El segundo hotizonte que ha condicionado profundamente la historiografia ha sido el pensamiento político. Éste ha interpretado el Mezzogiorno como una doble cuestión: como cuestión agraria y como cuestión napolitana.

Finalmente, la historiografia local urbana municipal ha sido un género intensamente cultivado en el Mezzogiorno desde la época del barroco hasta el positivismo del siglo XVIII.

Un excursus por sumario que sea «revela la riqueza de la cultura barroca también en la historiografía local del Mezzogiorno: un laboratorio en el que confluyen instrumentos de trabajo y motivos diversos, como estereotipos, imágenes ideales, intereses concretos para la organización y la articulación histórica de la sociedad urbanas. En las historias ciudadanas se teptesenta la más grande e importante historia militar, política y diplomática, de las hazañas de reyes, emperadores, príncipes, papas, arzobispos y grandes dignatarios feudales. Ciertamente a menudo el enfoque reenvía más a la función escénica que a la función material de la ciudad. Pero, a menudo también, reconocemos en esta historia local barroca el desartollo edilicio, la articulación social del poder, la recrecida importancia de los grupos y profesiones ligadas a la nueva organización estatal. "Así, de una parte la noción misma de bistoriografia, en relación misma con las vicisitudes urbanas, pertenece todavía a un universo temático y conceptual bastante amplio e indefinido; incorpora erudición, "anticuarismo", tratadística política, moralística, teología, etc.; por ello a menudo sus fragmentos reaparecen también en productos propiamente históricos. De otra parte, no obstante, en la variedad de los géneros barrocos, a diversos niveles de conocimiento, va abriéndose camino una nueva dimensión de la historia local urbana que alcanzará madurez y un elevado grado de complejidad con la cultura ilustrada napolitana de la segunda mitad del setecientos» ${ }^{14}$.

13 GaLASSO, G., Mexzogiorno medievale e moderno, Torino, 1965, págs. 61-135; idem, I/Mezzogiorno nella storia d'Italia, Firenze, 1984, págs. 15-107; idem, I/ Regno di Napok. Mezzogiorno angioino e aragonese, Turín, 1992.

14 MUSI, A., «Le piccole e medie città.,.», págs. 152-153.

Higpania, LVIII/2, núm. 199 (1998) 471-488 
Con Giuseppe Maria Galanti se estabiliza un esquema de historiografía local urbana que puede ser identificado en los siguientes elementos ${ }^{15}$ :

1. La importancia de la observación directa de los lugares es «más útil que la investigación metafísicas 16.

2. La idea-guía de la observación directa es la construcción material de los lugates, es decir, el complejo de geografia humana, instituciones y sociedad.

3. «El estado florido de una nación debe consistir en el campo y no en las ciudadess ${ }^{17}$.

4. La primacía de la Capital del Reino y la excesiva presión fiscal han hundido el desarrollo de las ciudades del Mezzogiorno.

5. Los objetos privilegiados de análisis pasan a ser: la corografia, la historia de la constitución, la geografía política, la producción, la antropología, las artes, las ciencias, la religión...

El tercer momento importante de la historia de la historiografia urbana del Mezzogiorno, después de la historiografia barroca y la ilustrada, es la historiografia positivista. En las numerosas monografias de ciudades y de áreas del Mezzogiono de Italia que fueron escritas en los últimos veinte años del siglo XIX, con resultados ciertamente no homogéneos pero de indudable interés, se da una fuerte conciencia del nexo entre historia local e historia general: una conciencia largamente advertida y difundida en la historiografia local del XIX tardío. Sobre la percepción exacta de dicho nexo, una serie de factores ejercian una influencia decisiva: el alto magisterio de una escuela histórica napolitana, de Carlo Troya a Bartolomeo Capasso; la difusión de las Deputazione y Società Historiche ciertamente nacidas y desarrolladas bajo la insignia del localismo; la formación crítica polidisciplinar de gtan parte de los estudios denominados locales; la difusión, también en ámbitos provinciales más distantes de los lugares de mayor producción y debate cultural de lo que Giuseppe Galasso ha llamado la (tevolución positivista), desarrollada de la mano de su específica vena filosófica y artífice de la creación de un «espíntu común del tiempo» ${ }^{18}$.

Las historias regionales y subregionales del Mezzogiorno, escritas en los decenios siguientes a la Unificación, reflejan una temperatura y una sensibilidad intelectuales del todo particulares, irrepetibles: sentimientos de identidad y significados culturales del término patria se confrontan y se confunden, gracias a la aceleración histórica provocada por la unidad nacional, en numerosas historias escritas por intelectuales meridionales depués de 1860 .

\section{EL CUESTIONARIO}

Los días 22 y 23 de Marzo de 1996 se desarrolló en Ischia un encuentro de estudios sobre el tema Las ciudades pequeñas y medianas en la bistoria del Mezzogiorno

15 GaLANTI, G. M., Descrizione dello stato antico ed attuale del Contado del Molisse, con un saggio storico sulla costituzione del Regno, Nápoles, 1781 [nueva edición, Bolonia, 1984, de la cual se cita].

16 Ibidem., pág. 13.

17 Ibidem., págs. 10-11.

18 GALASSO, G. Croce e lo spiritu del suo tempo, Milano, 1990, págs. 3-84 en particular.

Higpania, LVIII/2, núm. 199 (1998) 471-488 
moderno. El seminario, coordinado y dirigido por mí, organizado por el Dipartamento di Teoria e Storia delle Istituzioni de la Universidad de Salerno, ha reunido estudiosos provenientes de varias regiones del Mezzogiomo (Campania, Apulia, Basilicata, Calabria y Sicilia) y ha servido sobre todo para establecer un plan de trabajo colectivo para los próximos años. El resultado ha sido la propuesta de un cuestionario que se presenta a continuación: en él se incluyen los principales temas situados en el centro del debate historiográfico de los últimos años bien sea en relación con problemáticas o con la metodologia de la historia urbana.

Cuestionario

1. Ciudades-capital y centros menores: el monocentrismo napolitano frente al policentrismo siciliano.

2. Demografía y territorio: las dimensiones de los asentamientos y la dinámica de la urbanización.

3. Tipología de las ciudades y funciones urbanas.

4. Región geográfica, región administrativa, región histórica y formaciones urbanas.

5. Estado y ciudad.

6. De la «Universitas civium» al comune post-unitario: el estatuto jurídico de la ciudad.

\section{CIUDADES-CAPITAL Y CENTROS MENORES: EI MONOCENTRISMO NAPOLITANO FRENTE AL POLICENTRISMO SICILIANO}

¿Cuáles fueron las funciones históricas de Nápoles en la Edad Moderna? La primera función fue la de mercado: respecto a la actividad manufacturera, que se mantuvo siempre bastante limitada en los dos siglos españoles y se resolvió principalmente en el entramado del Estado, el mercado de consumo, fundado sobre el disfrute y el drenaje de tecursos de la periferia, y el mercado financiero, desempeñaron un papel bastante más importante en la atracción hacia Nápoles de capitales privados locales y sobre todo.extranjeros. Nápoles fue también centro político-administrativo del Reino, lo cual no significó sólamente la presencia de la Corte y el desarrollo de la burocracia, sino también la promoción de aquellas profesiones más ligadas a la máquina estatal, para las cuales sólo la ciudad de Nápoles estaba en condiciones de ofrecer una formación y una preparación más cualificada. Tercera función: la Capital fue un cuerpo privilegiado, el único sujeto «ciudad» dotado de potencialidad de contratación y de "partnership» con la Corona. Cuerpo privilegiado significaba no sólo sujeto político principal a los ojos de la Monarquía, y por consiguiente sede de inmunidades y prerrogativas que la Corona debía salvaguardar, sino también sede de servicios esenciales, que en Nápoles funcionaban mejor que en otras partes: abastecimiento, asistencia, etc., es decir, ese conjunto de setvicios comunitarios típicos de las ciudades-capital del Antiguo Régimen. La Monarquía española favoreció y exaltó el desarrollo de las funciones de la capital cediendo una cuota significativa del poder de centralización en las decisiones político-administrati-

Hispania, LVIII/2, num. 199 (1998) 471-488 
vas al Ministerio napolitano y asegurando a los Seggi el gobietno metropolitano ${ }^{19}$.

En el tránsito de la Casa de Aragón a la de los Habsburgo, también Sicilia estaba llamada a desarrolar como el Reino de Nápoles funciones importantes en la comunidad imperial: de un lado, la situación geográfica al sur del Mediterráneo aseguraba a la isla el papel de fortaleza del "Mare Nostrum», de vanguardia y primera defensa del Imperio; del otro lado, su gran reserva cerealícola hacía que se asignara a Sicilia la tarea de abastecer gran parte de los dominios de la Corona. Pero aquí el gobierno español del territorio debía vérselas con una formación histótica regional sensiblemente diferente de la del Mezzogiorno peninsular de Italia. Al protagonismo de la capital del Reino de Nápoles hacía de contrapunto el policentrismo regional siciliano. A lo largo del siglo XVI, la población siciliana fue principalmente concentrándose en las ciudades: se constituyó un área regional con una tasa de urbanización entre las más elevadas en la Europa de la época. Según los datos del «rilievo» de 1583, de sus cerca de un millón de habitantes, 400.000 se concentraban en 18 ciudades con más de diez mil: es decir, en las ciudades medias que precisamente faltaban en el Mezzogiorno peninsular. $\mathrm{Y}$ otros 280.000 se concentraban en ciudades pequeñas con más de cinco mil habitantes. Si de la dimensión cuantitativa de los centros se pasa a observar las funciones urbanas, la diferencia con la situación del Mezzogiono peninsular emerge con plena evidencia: centros como Palermo, Messina, Trapani, Siracusa, Nicosia, Modica, Enna, Catania y ottos muchos poseian funciones administrativas, civiles, religiosas, comerciales y productivas complejas y articuladas ${ }^{20}$. La fuerte urbanización misma de Sicilia generó conflictos y tensiones que desembocaron en el ciclo de revueltas del siglo XVIII. En paralelo con esta fuerte urbanización habían ido consolidándose en Sicilia dos modelos de organización económica y tertitorial. Palermo representaba la Sicilia del cereal, Messina la Sicilia de la seda. Ambos protagonistas de un balance demográfico excepcional entre el 1505 y el 1606 - Messina y sus aldeas pasaron de 30.000 a 100.000 habitantes, Palermo de 25.000 a otros $100.000-$ reivindicaban el liderazgo isleño: la primera como centro de las funciones político-administrativas más importantes, mas también como corazón del poder feudal de la isla, pues los vértices superiores de los tribunales estaban controlados por la nobleza del latifundio cerealístico; la segunda como celosa custodia de la autonomía, de los privilegios de una butguesía mercantil progresivamente transformada en patriciado urbano. Ambas oligarquías insistían en la naturaleza de la relación entre Sicilia y España: Sicilia era un «reyno pactionado», libremente confederado con la corona española, y que se sabía siempre opuesta a cualquier tentación de «castellanización».

\footnotetext{
19 Véase para todas las cuestiones aqui planteadas, mis siguientes contribuciones: La rivolta di Masianello nella scena politica barocca, Nápoles, $1989 ;$ Mezrogiorno spagnolo. La via napoletana allo Stato moderno, Nápoles, 1991; «Stato e stratifićzioni siciali nel Regno di Napoli», Chio.

20 LIGRESTI, O., Sicilia moderna. La città e gli womini, Nápoles, 1984; idem (ed.) I/governo della città. Patriziato e politica nella Sicilia moderna, Catania, 1990.
} 


\section{DEMOGRAFÍA Y TERRTTORIO: LAS DIMENSIONES DE LOS ASENTAMIENTOS Y LA DINÁMICA DE LA URBANZZACIÓN}

El Cinquecento es el siglo que ha visto producirse transformaciones profundas en la geografía urbana europea. En el medievo las grandes ciudades tenían una población comprendida entre los diez mil y los cincuenta mil habitantes, las ciudades de tamaño mediano contaban entre dos mil y diez mil, y las pequeñas menos de dos mil. En torno del año 1400 existían sólo dos ciudades grandes comprendidas en un arco entre los cien mil y los doscientos mil habitantes: París y Nápoles. Un siglo después, las ciudades grandes insertas en esta banda de oscilación eran cuatro: París, Nápoles, Venecia y Milán. Alrededor del 1600 existía una nueva jerarquía, con diez grandes ciudades entre cien mil y doscientos mil habitantes (Londres, Venecia, Lisboa, Milán, Amsterdam, Roma, Palermo, Messina, Sevilla y Amberes) y dos megalópolis en torno a los trescientos mil habitantes (París y Nápoles).

Estudiando las vicisitudes de los asentamientos y del territorio, Giuseppe Galasso ha podido argumentar que uno de los efectos más importantes de la gran crisis demográfica del siglo XIV fue la disminución registrada en el número de comuni meridionales. "En la primera ocasión en que podemos valorar el fenómeno, la que ofrece la enumeración de 1505 proporcionada por Giustinia$\mathrm{ni}$, la diferencia en las cifras es impresionante: en lugar de los 2.356 comuni existentes en 1268, ahora aparecen 1.462, con una disminución de cerca del 40 por ciento. La crisis no puede haber carecido de tepercusiones importantes sobre la consistencia demográfica media de los comunes meridionales, provocando un proceso de concentración relativa de los habitantes que, por lo demás, parece característica de la época sobre todo el área europea afectada por la crisis. Con toda probabilidad entonces - continúa Galasso- una gran parte de los centros meridionales de llanura y de montaña debieron asumir definitivamente o prepararse pata asumir esa fisonomía de dormitorios campesinos que habría de caracterizarlos después a través de los siglos, al reclamar para sí la población esparcida por el campo o en centros periféricos menores durante la fase de expansións ${ }^{21}$. Entre el siglo XVI y el XVIII la dimensión predominante entre los comuni meridionales - altededor del 70 por ciento- es inferior a los ocho mil habitantes. Sólo tres ciudades - Bari, l'Aquila y Reggio Calabriasuperan los veinte mil habitantes. «Las ciudades medias eran por consiguiente las que se situaban entre los siete mil y los veinte mil habitantes: poco más de $60 \mathrm{y}$, por otro lado, sin destacar decisivamente respecto de las dimensiones de los centros menores ${ }^{22}$.

Podemos por consiguiente ya aislar, en la historia del Mezzogiorno continental, una práctica ausencia de ciudades medianas, la existencia de un continuum cam-

21 GaLAsso, G., L'altra Europa. Per un'antropologia storica del Mezzogiorno d'Italia, Milán, 1982, pág. 37.

22 Ibidem, pág. 40.

I lispania, LVIII/2, núm 199 (1998) 471-488 
pa-ciudad, la ausencia de polos de atración ciudadana aparte de Nápoles y la elevada demanda de funciones urbanas concentradas en la capital del Reino.

\section{TIPOLOGIAS DE CIUDAD Y FUNCIONES URBANAS}

Se ha escrito que wal contrario que las ciudades del Norte, el comune meridional no gobierna el campo propio, ni puede considerarse una isla en un mar feudal (...) En el Mezzogiorno las ciudades estaban íntimamente unidas al territorio rural por una estrecha red de interdenpendencia. En una variedad de situaciones económicas y productivas, el comune dependía del campo para la formación de la renta y de la riqueza (...)».

Como ya ha sido observado anteriormente, en el Mezzogiorno continental «la subordinación a la capital es completa, con efectos generalmente negativos para el desarrollo de las ciudades meridionales (...) Un sistema urbano macrocefálico, por consiguiente, dominado por la agregación principal y caracterizado por un tendencial isomorfismo de las ciudades de provincia, ninguna de las cuales superaba los veinte mil habitantes» ${ }^{23}$.

Esto constituye el esquema o el cuadro de referencia general del problema, por así decir. Pero la tipología de ciudades meridionales en relación con sus funciones urbanas se presenta todavía más articulada respecto de la estaticidad del esquema.

No hay duda de que también en el Mezzogiorno urbano son identificables ciudades con una tasa bastante elevada de funciones urbanas: se trata, obviamente, de aquellas ciudades de Apulia y Sicilia que tienen una relación bastante intensa con centros comerciales extranjeros y que, a pesar de entrar en circuitos económicos bastante amplios, constituyen a menudo el centro de gravitación de su hinterland. Pero un nivel elevado de funciones urbanas muestra también otras ciudades que son residencia de oligarquías municipales, sede de funciones administrativas periféricas, de funciones religiosas, de funciones militares: el análisis de la relación ciudad-grupos sociales resulta particularmente importante en este caso para comprender la dinámica de las funciones urbanas y su desarrollo diacrónico. La diferencia entre esta segunda tipología de ciudades y la primera es la característica geo-económica: estas ciudades no consiguen llegar a ser centros de la realidad provincial circundante, es decir, no desarrollan la función de coordinación económica del territorio.

Una tercera tipología la ofrecen ciudades que en la formación y en el desarrollo urbano están profundamente condicionadas por una función económica específica: ciudades protoindustriales (textiles, alimenticias, etc.) con funciones de coordinación del trabajo aldeano ${ }^{24}$; ciudades agro-pastoriles, etc.

23 DI CIOMMO, E., «L'urbanizzazione del Mezzogiorno nella prima metà dell'Ottocento. Aspetti storici e problemi di ticercar, Storia urbana , 45, 1988, págs. 79-81.

24 MUSI, A., «Manifatture, preindustria e protoindustria in Pxincipato Citra (secc. XVI-prima metà XIX)»; Rassegna Storica Salernitana, 25, 1995, págs. 157-174. 
En suma, reencontramos la presencia en el Mezzogiorno moderno de realidades urbanas en las cuales es bastante estrecha la relación entre identidad artesana y agricultura: son las ciudades dotadas de aldeas con papel autónomo definido y relativamente integradas. En el Reino de Nápoles y en Sicilia es notable el número de ciudades dotadas de aldeas: ipensemos en Cosenza que cuenta con 85! En el citado seminario de Ischia, Giovanni Muto ha planteado tres hipotéticas funciones de las aldeas: abastecimiento de productos agrícolas para la comunidad ciudadana, sede de inversión inmobiliatia y amortiguador entre el dominio regio y el feudo, una especie de zona colchón que entraba probablemente en las miras expansionistas tanto de la ciudad como del señor feudal. Ciertamente no todas las aldeas poseen una relación funcional con la ciudad, de manera que la relación ciudad-aldea resulta problemática. Un ejemplo estudiado por mí es el de las aldeas de Salerno. Hay en ellas una constante: la preponderancia demográfica respecto del centro urbano. En las aldeas habita casi el doble de habitantes que en la ciudad. Las aldeas son 19 a mediados del siglo XVII. Se encuentran esparcidas por el valle del Irno. Su economía presenta una estructura dual. Las aldeas orientales están caracterizadas por una economía preferentemente agrícola organizada en la dehesa (masseria) de gestión familiar, que consiente también cultivos especializados. Se trata a menudo de pequeñas propiedades de explotación directa o dejadas en arrendamiento, que no recaen sobre la jurisdicción feudal, o de propiedades eclesiásticas que tienen casi siempre como cabeza a la Mesa arzobispal de Salerno, concedidas a menudo en enfiteusis. Las dehesas son de cultivo mixto cerealícola y arbóreo, permiten también la ganadería porcina y bovina. Estas dehesas de tipo hacienda están explotadas por arrendatarios adinerados y más a menudo por propietarios cultivadores directos que se sirven de mano de obra asalariada estacional, los braciali, y que cometcializan por sí mismos, pero en ocasiones también por intermediarios, los productos agrícolas, exportando sobre todo cítricos y miel bien hacia Salerno, bien hacia Avelino, Nápoles y Castellammare por mar. Las aldeas de la vertiente occidental del valle del Ino son en cambio de economía mixta: en ellas es preponderante la manufactura de la lana y el curtido de la piel. El área de comercio de la manufactura está comprendida entre Salerno, el campo nocerino-sarnese, Irpinia, Sannio, Tavoliere y Adriático, siguiendo el trazado de la vía Appia. La relación entre la ciudad de Salerno y sus aldeas es bastante intensa. Las aldeas agrícolas son vitales para el aprovisionamiento. El clero, la nobeza y los burgueses salernitanos tienen aquí la base de su riqueza. La integración entre las aldeas manufactureras de la zona occidental y la ciudad es elevada y alimenta gran parte del volumen comercial. También el sistema de comunicaciones viarias favorece la integración.

Sin embargo, no conviene enfatizar demasiado esta integración. Lo que aparece en esta zona con claridad es una multiplicidad de circuitos, relativamente autónomos entre sí, con canales diversos de producción y cometcialización, a menudo externos a la ciudad de Salerno y no controlados por ella. En suma, Salerno aparece incapaz de cualificarse como momento de organización y de síntesis de un área de la cual sólo raramente constituye el centro de gravedad.

Higpania, LVIII/2, num 199 (1998) 471-488 


\section{REGIÓN GEOGRÁFICA, REGIÓN HISTÓRICA, REGIÓN ADMINISTRA'TIVA} Y FORMACIONES URBANAS

¿Existe en Italia la región como entidad objeto de historia? ¿Qué papel ha desempeñado la ciudad en la definición de la identidad de la región?

Está bastante aceptada la distinción, efectuada por el geógrafo Lucio Gam$\mathrm{bi}$, entre regiones jurisdiccionales y regiones funcionales. Las primeras caracterizarían buena parte de la península y de las islas italianas: aqui la región repite un filo económico-jurisdiccional más o menos sobresaliente y se distingue de manera exclusiva por dialectos, formas de vida y de asentamiento, costumbres, comportamientos. La región funcional se encuentra en el Norte: su identidad mejor definida permite una articulación más moderna de funciones políticoadministrativas ${ }^{25}$.

Sobre la estela de Gambi otro geógrafo, Leonardo Rombai, ha argumentado recientemente que tanto las provincias como las regiones en Italia fueron individualizadas sobre la base «de meras prácticas de regionalización geogrático-estadísticar: son aquéllas retazos de espacios en clave puramente administrativa. La región histórica es otra cosa: una serie bastante variada de «lugares, microcosmos y pequeñas patrias locales (aldeas y centros mínimos, centros menotes, barrios históricos y anónimas periferias urbanas, ambientes rurales, campos urbanizados o industrializados, litorales turísticos, montañas con valles, etc.) ${ }^{26}$.

En el área meridional de la península itálica, en la Edad Moderna y hasta el período preunitario, la región bistórica está aún en gran parte por definir: ésta «es casi siempre privada de una unidad fisiológica y morfológica propia y se presenta como resultado de un difícil entretejimiento entre articulación geográfica, articulación jurisdiccional y articulación político-administrativa, enlace que ha venido evolucionando históricamente hasta alcanzar la forma actualls, 27

Para los objetivos de nuestro análisis se presenta también particularmente interesante la tipología histórica de la regionalización italiana propuesta por $G$. $\mathrm{Galasso}^{28}$. Él distingue entre líneas de evolución diversas. La más importante, la que contribuye a conferir fisonomía unitaria a la experiencia regional, es el paso del Estado de base ciudadana al Estado de base regional. En sustancia se trata de las regiones funcionales de las que habla Gambi: Lombardia, Véneto, Ligu-

25 GAMBI, L., «I valori storici dei quadri ambientali», en AA.VV. Storia d'Italia Einaudi, I: I caratteri originali, Turin, 1972, pag. 58.

26 ROMBAI, L., «L'Italia come espressione geografica. Stato e autonomie locali dopo l'unificazione nazionale» en BERTELLI, S. (ed.), La chioma dello vittoria. Scritti sulla identità deglt Italiani dell'Unità alla seconda Repubblica, Florencia, 1997, págs. 50-51.

27 MUSI, A., «Regione storica, provincia e società del Mezzogiomo moderno", Quaderni Sardi di Storia, 1, 1980, págs. 83-84.

28 GALASSO, G., «Prefazione» a Brancaccio, G. Primato di Napoli e identità campana dell Ttalia unita, Lanciano, 1994, págs. VII-VIII. 
ria, Toscana. El Piamonte se presenta como el único caso de coincidencia entre región y Estado de base dinástica. Si se observa la relación entre provincia y región, es posible distinguir tres tipologías: una de coincidencia (Umbria, las Marcas, Molise, Basilicata), otra de antagonismo (Trentino y Alto Adige), y otra de combinación de dos provincias vecinas que han dado vida a una región (Abruzzo, Calabria). Mientras las islas, Sicilia y Cerdeña, se caracterizan por una fuerte individuación, existen otras experiencias de engrandecimiento que Galasso define como «agregación problemática«: Lazio, Emilia-Romagna y Campania.

Es posible reconocer en la historia del Mezzogiorno continental regiones en las que la identidad más relevante ha sido y es la identidad ciudadana. Esto ha sido resaltado ya previamente: Apulia, Campania, Calabria, Abruzzo y Sicilia están todas dotadas, en medida y modalidades diferentes en las distintas épocas históricas, de indudable vivacidad urbana. Pero en la mayor parte de ellas la identidad ciudadana no ha sido suficientemente fuerte y condicionante como para calificar y caracterizar el espacio regional. Existen dos sólas excepciones en dicho cuadro: Campania y Sicilia. En el primer caso, la primacía de Nápoles es el factor más poderoso de identidad de la región de Campania, que condiciona las dinámicas mismas de desarrollo de los otros centros utbanos. En el segundo caso, el policentrismo urbano es el factor que mejor caracteriza el desarrollo regional porque se une a un complejo de funciones interconectadas. Interconexión obviamente no significa integración: al contratio, la relación entre las ciudades sicilianes ha sido a menudo conflictiva, como demuestran las revueltas del siglo XVII.

\section{ESTADO Y CIUDAD}

«Es la relación particular con el Estado en el trascurso de los siglos - ha sido escrito- la clave de bóveda del sistema urbano meridional de la Edad Moderna (...) Las ciudades que se han beneficiado en el tiempo de concesiones y privilegios de naturaleza varia han resultado finalmente tener una mayor complejidad social e institucional: a) económica, en relación con el poder de gestión y de disfrute de la propiedad fundiaria (Altamura, San Severo, Cosenza, Teramo) o bien de exenciones fiscales y facilidades aduaneras en el ejercicio del tráfico mercantil (Barletta y en general los puertos del litoral adriático); b) política, relativa a la potestad de carácter público como por ejemplo el derecho de acuñar moneda (Cosenza, Catanzaro, Sulmona, Capua, Lanciano, Gaeta) o bien prerrogativas en el ámbito del poder municipal; c) religiosa, con referencia particular a la instalación de sedes episcopales. La concesión de estos ptivilegios se traduce a menudo en un corpus específico de leyes, de instituciones y de valores munipales que confieren un estatus de ciudad a las aglomeraciones, las distingue de los burgos, aldeas y localidades menores del Reino y se refleja,

Hispanta, LVIII/2, núm. 199 (1998) 471-488 
dentro del perfil urbanístico, en la estructura morfológica y en la diversa dignidad arquitectónica de los lugares poblados» ${ }^{29}$.

Desde este punto de vista, el término «a quo» está constituido por la dominación aragonesa para el reino de Nápoles y durante los primeros decenios del siglo XV para Sicilia. Las ciudades adquieren en dicho período un papel de partnership en la relación con la Corona. El Quattrocento siciliano es el siglo de las ciudades. En la isla, la Corona con sus nuevas exigencias fiscales, constituye un poderoso factor de promoción urbana. «Un fenómeno de extraordinario relieve de este período es de hecho la transición entre el segundo y el quinto decenio del siglo - con una decidida aceleración después de 1432-1433- de una organización informal de la sociedad urbana a una estructura social y política ordenada según categotías corporativas y de estamentos: por consiguiente, por primera vez, según criterios socio-políticos de adscripción ${ }^{30}$. La Corona desarrolla una función de mediación en los conflictos de redistribución del poder económico y político que estallan en las ciudades.

En el Reino de Nápoles, incluso durante los dos siglos del gobierno español, la relación entre Estado y ciudad se mantiene fuertemente condicionada por la caracterización primordialmente fiscal de los sujetos urbanos. En la estrategia de la Monarquía española para el Reino de Nápoles no hay espacio para las ciudades medias y pequeñas: haciendo salvedad de la naturale$z a$ fiscal de la relación, la Monarquía conserva una actitud de fundamental neutralidad hacia los conflictos de poder y de intereses que se pueden verificat en la realidad urbana del Mezzogiorno. La ciudad pequeña y mediana no es considerada por la monarquía un socio eficaz para el gobierno político del territorio. En la lógica de los compromisos que caracteriza la relación entre España y el Reino de Nápoles, sólo la Capital, en el marco de sus estamentos representados, funciona como contrapeso al poder económico y social de la aristocracia feudal: y sólo se reconoce a la Capital un papel de socio con Ia Corona. Por consiguiente entonces, la telación política entre el Estado y la ciudad en el Mezzogiorno continental de Italia, durante los primeros siglos de la Edad Moderna, aparece bastante limitada en su desarrollo, concentrada a menudo estrictamente en el terreno fiscal: en él se negocia de un lado, el de la Monarquía, consenso, y del otro, el de la ciudad, privilegios, inmunidades, exenciones. Y así el Estado fiscal no es sólo una hidra que absorbe recursos, sino también un factor de redistribución de la riqueza. Es obvio que los efectos de esta dinámica ponen en discusión la aparente neutralidad del Estado napolitano en los sistemas de relaciones y de conflictos sociales urbanos. Sobre esta hipótesis de trabajo la investigación debería

29 DI CIOMMO, E., op. cit., pág. 81; Véase también del mismo autor, (Piccole e medie città meridionali tra antico regime e periodo napoleonicon, en AA.VV. Villes et territoire pendant la perode napoléonniene (France et Italie), Roma, 1987, págs. 369 y sigs.

30 EPSTEIN, S. R., "Conflitti redistributivi, fisco e strutture sociali (1392-1516)» en AA.VV. (a cura di BENGINGO, F y TORRISI, C.), Élites e potere in Sicilia dal Medioero ad oggi, Catanzaro, 1995, págs. 37-38. 
comenzar a buscar respuestas que, en el estado actual, son todavía meramente aproximativas.

\section{DE LA \&UNIVERSITAS CIVIUM* AL COMUNE POSTUNITARIO: EI. ESTATUTO JURIDICO DE LAS CIUDADES}

El análisis histórico-lexicológico demuestra la permanencia del estatuto jurídico de las ciudad meridional como universitas civium ${ }^{31}$. Al menos hasta mediados del siglo XVIII, los caracteres de la universitas se mantienen bastante constantes. En sintesis son los siguientes:

a) el carácter "privatístico» del comune: se trata de sociedades privadas que no pueden gozar de ninguna soberanía, hallándose toda ésta concentrada en el Estado, es decir, en el rey. Todavía en la segunda mitad del Setecientos Pecori establece una analogía casa-familia-universitas, tanto para las funciones cuanto para las competencias: «Las universitates transfieren en sus gobernantes la facultad de imponer cargas sobre quienquiera que sea según la industria y los bienes que posea, y de obligarle a dar cuenta de ellos, destinando al efecto las personas que sean menester, como administradores de cosa ajenas. Pero, continúa Pecori, «esto no tiene nada de público como no lo tiene tampoco el Padre cuando distribuye los asuntos de la casa entre sus familiares》 ${ }^{32}$. En este contexto, gobierno y administración de la universitas forman parte del universo semántico de la tutela.

b) La tutela del principio de la soberania y de la centralización administrativa: aunque se le reconocen algunas funciones públicas de autonomía, el comune no puede sustraer poder a la esfera central de la soberanía, que se mantiene una e indivisible.

c) El fundamento de la organización jurídica del comune-ciudad es en su naturaleza asociativa en la representación de intereses y de derechos comunitarios.

Entre mediados del siglo XVIII y mediados del XIX las transformaciones que se producen en la estructura y en la concepción del comune-ciudad, están ligadas a la formación del concepto de territorio, a la progresiva definición del comune como aparato, máquina administrativa, y a la recrecida autonomía de sus competencias de naturaleza administrativa y civil.

\section{CONCLUSIÓN}

Debería haber quedado a estas alturas más claro el objeto de investigación. Se utilizan las nociones de ciudad pequeña y ciudad mediana aludiendo no al simple parámetro dẹmográfico, insufiente para definir la identidad de nuestro objeto

31 MUSI, A., «L'amministrazione locale dalla università d'antico regime alla Comune del decennion en AA.VV. I/ Principato Citeriore tra ancien règime e conquista francese: il mutamento di una realtà periferica del regno di Napoli, Salerno, 1993, págs. 35-45.

32 PECORI, R, Del privato governo dell'Università, Nápoies, 1770 , pág. 2.

Hippania, LVIII/2, núm 199 (1998) 471-488 
de estudio, sino para un conjunto de tipologías y funciones urbanas, sujetas a un complejo de variables dependientes tanto diacrónicas como sincrónicas. Es necesario evitat a lo largo del recorrido de la investigación dos opciones contrapuestas pero igualmente sesgadas: el exceso de modelización y la tentación de escribir muchas historias concretas de ciudades. En el centro de atención deben estar, pues:

- la tipología de asentamientos (relación ciudad-campo, ciudad-aldeas...)

- las funciones económicas (ciudades mercantiles, ciudades protoindustriales, ciudades agro-pastoriles...)

- las funciones religiosas.

- las funciones político-administrativas.

- las funciones de servicios.

- la relación ciudad-grupos sociales.

- la jerarquía entre las diversas funciones urbanas.

Las cuestiones más importantes que funcionarán de ideas-guia de la investigación son las siguientes:

- La relación Capital-centros menores: se confrontará el monocentrismo peninsular meridional con el policentrismo insular siciliano; se procederá por consiguiente a una revisión de la relación centro-periferia que no puede ser ya vista en los términos tradicionales como una mera dependencia de la segunda respecto del primero, sino como una más compleja interacción.

- La atención a los contextos: una hipótesis de trabajo que se puede verificar es la ausencia histórica en el Mezzogiorno de un sistema urbano como parte de un más amplio sistema urbano italiano. No obstante, la observación de la pluralidad de centros urbanos en el Mezzogiorno es sólo el primer paso, de carácter descriptivo, por así decir, del trabajo. En un estadio posterior se sitúa una atenta y delicadísima contextualización de la experiencia ciudadana en el Mezzogiorno, que tenga en cuenta sobre todo la incidencia en el sistema de relaciones de los condicionantes feudales y estatales.

- Las permanencias y las transformaciones en las jerarquias urbanas. aunque en el Mezzogiorno no se ha formado un sistema urbano, sin embargo se han creado retículas urbanas, «islas» más intensas de urbanización: explicar las permanencias, transformaciones y mutaciones de función de estos sujetos debería ser tenido en cuenta en la investigación.

- La autoconsciencia ciudadana la historiografía local urbana ha de ser ampliamente empleada, no sólo como fuente sino también como sujeto autónomo de estudio. La historia de la historiografía urbana y de un variado género literario que puede ser comprendido bajo la voz de descripciones responde a cuestiones de diversa naturaleza y todas igualmente importantes: las crónicas, las memorias, las descripciones de las ciudades, las reconstrucciones cartográficas mismas envían mensajes sobre la 
percepción que las ciudades tenían de sí mismas. El tono de estas historias ciudadanas permite la alusión a elementos mitológicos e históricos sobre los orígenes de las ciudades, a los aspectos topográficos y arquitectónicos, a un posible y verificable orden ciudadano que se puede medir en las construcciones, en la estructura viaria, hasta en la edificación de un teatro. Se analizan también las tendencias recurrentes, en coyunturas de fuerte centralización estatal (reformismo ilustrado, centralización político-administrativa inmediatamente posterior a la Unidad), al patriotismo ciudadano, paradigma ejemplar de las historias urbanas.

- La periodización: el término «a quo» de nuestra investigación se sitúa en la Baja Edad Media. En el siglo XV son ya reconocibles, bien sea las vías de la legitimación jurídica de las ciudades meridionales, bien la definición de sus funciones urbanas, bien una particular configuración de sus relaciones con el Estado (esta última vertiente discurre paralela a la trayectoria de las ciudades sicilianas y la de las ciudades peninsulares del Mezzogiorno de Italia). El término uad quem» es el período comprendido entre la era napoleónica y la reestructuración administrativa de la primera mitad del siglo XIX, período no sólo de confirmación y de reforzamiento de estatus urbanos adquiridos, sino también de nuevos equilibrios y jerarquías.

De todo cuanto precede, se deduce que la metodología empleada para esta investigación no puede ser sino amplia y debe incorporar economía, sociedad, política y cultura en una visión bastante extensa de sus relaciones.

Traducción de Pablo Sánchez León 